\title{
Del espacio público al privado. Un análisis del problema de urbanización desde la comunicación ambiental
}

\section{From public to private space. An analysis of the urbanization problem from environmental communication}

Analí Sánchez Paredes*

Universidad Anáhuac México

Av. Universidad Anáhuac núm. 46, Col. Lomas Anáhuac,

C.P. 52786, Huixquilucan, Estado de México

Rafael Tonatiuh Ramírez Beltrán ${ }^{* *}$

Universidad Anáhuac México

Centro de Investigación para la Comunicación Aplicada (CICA)

Av. Universidad Anáhuac núm. 46, Col. Lomas Anáhuac,

C.P. 52786, Huixquilucan, Estado de México

Editor: Rogelio del Prado Flores ilana404@yahoo.com.mx

https://orcid.org/0000-0002-5583-0760

rramirez@nahuac.mx

https://orcid.org/0000-0002-1968-9755

https://doi.org/10.36105/stx.2019n3.03

\section{RESUMEN}

E

1 propósito del trabajo es identificar la información que comparten algunas páginas gubernamentales y asociaciones civiles relacionadas con el medio ambiente, la educación ambiental y la sustentabilidad en la red sociodigital Facebook; asimismo, observar el tipo de publicaciones realizadas durante un lapso de cinco días del mes de octubre de 2019 para categorizarlas; de esta manera inferir el desenvolvimiento de las interacciones entre las instituciones u organizaciones y los usuarios a través del medio digital para revelar tendencias, relevancias y sesgos en la comunicación ambiental que difunden. Los resultados que se obtuvieron demuestran que las páginas de instituciones oficiales son quienes publican con mayor frecuencia, por lo que los usuarios responden con alguna reacción o like y comparten el contenido.

\footnotetext{
* Doctorante. Doctorado en Investigación de la Comunicación por la Universidad Anáhuac México. Maestra en Educación Ambiental (UPN-095).

** Doctor en Administración Pública. Profesor de la Facultad de Comunicación e Investigador del Centro de Investigación para la Comunicación Aplicada (CICA) de la Universidad Anáhuac México.
} 
Palabras clave: espacio público, espacio privado, urbanización, crisis ambiental, comunicación ambiental, Facebook.

\section{ABSTRACT}

The purpose of the work is to identify information shared by some government pages and civil associations related to the environment, environmental education and sustainability on the social-digital Facebook network; also observe the type of publications made over a five-day period of October 2019 to categorize them; in this way infer how interactions between institutions or organizations and users are developed through the digital medium to reveal trends, relevances and biases in the environmental communication they disseminate. The results that were obtained show that the pages of official institutions are the ones who publish most often, so users respond with some reaction or like and share the content.

Keywords: public space, private space, urbanization, environmental crisis, environmental communication, Facebook.

\section{INTRODUCCIÓN}

La aceleración social que se ha dado desde la Revolución industrial en el siglo XVIII ha propiciado que los habitantes del planeta vivan una serie de acontecimientos que perjudican su salud y dañan el entorno donde viven. A lo que antes se le llamaba progreso, Adorno y Horkheimer le llaman desencantamiento del mundo, al referirse al proceso de Ilustración como un proceso de progresiva racionalización, abstracción y reducción de la entera realidad al sujeto bajo el signo del dominio del poder (Horkheimery Adorno, 1998, p. 13). Esto quiere decir que el deseo de dominación del ser humano hacia la naturaleza ha incitado actos de sobreexplotación y degradación de los recursos naturales pero, además, injusticias sociales, por los procesos de acumulación de riqueza que afectan a los sectores de la población más vulnerables.

Este artículo parte del tema de la construcción de los espacios públicos y privados en las ciudades y cómo las urbanización devela problemáticas que han originado una serie de síntomas ambientales que evidencian una crisis ambiental, que pone en riesgo las formas de vida en nuestro planeta; se retoma el concepto de espacio público y espacio privado para encontrar las causas por las que las personas han utilizado internet y redes sociodigitales 
como espacio de participación y entretenimiento; se considera que la educación ambiental y la sustentabilidad son una opción para el cambio de actitudes y combatir la masiva destrucción, natural y social, del planeta; finalmente, se aborda el tema de comunicación ambiental, donde la educación ambiental, como interdisciplina, se ha incorporado al uso del ciberespacio como medio de comunicación.

\section{ESTADO DEL ARTE: LA URBANIZACIÓN Y LA CRISIS AMBIENTAL}

La civilización, ahora en crisis, tiene una base de desarrollo en las ciudades. Los otros elementos fundamentales del modelo son la industria, la concentración de la población, la forma de producción y consumo, la concentración de la riqueza y un modelo de saber ligado a la ciencia y la tecnología.

Sin embargo, es en occidente, en la modernidad, el espacio en el que se desarrolla la vida social. La evolución de la urbe es, con frecuencia, imperceptible en sus dimensiones: crece todos los días. Observar enormes ciudades con majestuosa arquitectura, enormes rascacielos, parques, centros de diversión, centros comerciales lujosos, casas y departamentos y transportes veloces; pero ¿qué hay detrás de la construcción de dichas ciudades?, ¿quién absorbe los gastos?, ¿qué problemas originan?, ¿la población satisface sus necesidades y es feliz?

Se crean ciudades para las personas, no obstante, de los recursos naturales que existen, el suelo es uno de los más significativos debido a que se constituye como un factor indispensable del patrimonio natural, sin embargo, históricamente ha sido subestimado socialmente (Soto Cortés, 2015, p. 128); al crear o transformar las ciudades, los capitalistas también piensan en la construcción de nuevas formas de vida y nuevos tipos de habitantes para las nuevas ciudades: viviendas, almacenes, centros culturales, hospitales, aeropuertos, autopistas, lo cual genere consumo; no todos los ciudadanos tienen los recursos económicos para ese tipo de vida, y comienzan a envolverse en créditos y préstamos interminables de pagar. El malestar es consecuencia del efecto devastador que el modelo dominante de globalización tiene en los países en desarrollo, especialmente sobre los pobres en esos países, el proceso de urbanización en las principales ciudades del mundo está experimentando una gran transformación espacial, que en los países en vías de desarrollo corresponde con un crecimiento demográfico y en los países desarrollados tiene que ver con transformaciones en el consumo del espacio (Vergara, 2009, p. 36).

Ello explica Mireia Bonilla cuando afirma que la riqueza está cada vez más concentrada en menos manos y cómo la brecha entre personas ricas y pobres está creciendo y poniendo 
en peligro la lucha contra la pobreza, debido a que son 26 las personas que poseen la misma riqueza que los 3800 millones de personas que componen la mitad más pobre de la humanidad (Bonilla, 2019, párr. 1). Los pobres son los menos privilegiados, son marginados e incluso, exhiliados a vivir en la periferia de las ciudades, donde las viviendas son viejas, e incluso peligrosas, con problemas de servicios públicos, de transporte, de seguridad, entre otros. David Harvey menciona que "la calidad de la vida urbana se ha convertido en una mercancía para los que tienen dinero" (2013, p. 34); se vive en una sociedad de consumo donde la población se vuelve narcisista, hedonista, hiperconsumista,vive con ligereza y busca una felicidad paradójica, como diría Lipovetsky (2007).

Todos los requerimientos del proceso de urbanizacion (vivienda, transporte, servicios públicos) requieren de un consumo excesivo de recursos naturales que da pauta a la aparición de síntomas ambientales como la desaparición de los ecosistemas, la pérdida de la biodiversidad, el agotamiento del agua dulce y de los combustibles fósiles, los incendios forestales, la erosión, la lluvia ácida, la contaminación (del suelo, el aire, el agua, auditiva y visual), el adelgazamiento de la capa de ozono, el cambio climático, la concentración de la población, son sólo algunos ejemplos que se observan en varios lugares del planeta y que evidencian una crisis ambiental. Para Enrique Leff, la crisis ambiental es una crisis del conocimiento que ha construido un mundo insustentable (Leff, 2011, p. 6); no obstante, menciona que surgen nuevos conflictos y se agudizan viejos problemas sociales como el choque entre culturas, el fundamentalismo ideológico-político, la violencia social y el terrorismo; la inseguridad alimentaria, la desigualdad social y la pobreza; la corrupción de la sociedad y la narcotización de la economía y la política; la equidad de género, los nuevos derechos humanos, el pensamiento ecológico y complejo (p. 10).

El Manifiesto por la vida. Por una ética para la sustentabilidad, menciona que:

La crisis ambiental es una crisis de civilización. Es la crisis de un modelo económico, tecnológico y cultural que ha depredado a la naturaleza y negado a las culturas alternas. El modelo civilizatorio dominante degrada el ambiente, subvalora la diversidad cultural y desconoce al Otro (al indígena, al pobre, a la mujer, al negro, al Sur) mientras privilegia un modo de producción y un estilo de vida insustentables (Manifiesto por la vida. Por una ética para la sustentabilidad, 2002, p. 1).

Por otro lado, Roger Martínez encuentra como causas a la crisis socio-ambiental, el papel destructivo de los seres humanos en la naturaleza; la idea aristotélica de lo humano como centro, separado de lo natural; el concepto antropócéntrico en la relación especie humana-naturaleza; la relación humana con la biosfera; y, la visión mercado-céntrica en la relación sociedad-naturaleza (Martínez Castillo, 2012, p. 71); Harvey asegura que "el 
proceso urbano es ahora planetario y está atravesando por todo tipo de fisuras, inseguridades y desarrollos geográficos desiguales" (2013, p. 45); hace referencia a una crisis urbana; asimismo, Edgar Morin llama policrisis a muchas crisis interramificadas y enredadas, la crisis del desarrollo, la crisis de la modernidad, la crisis de todas las sociedades; es por eso que no se puede seleccionar un problema número uno, al que todos los demás quedaran sudordinados, hay muchos problemas vitales (Morin y Kern, 2006, p. 108).

La urbanización no sólo genera una crisis ambiental y social, sino que también ha originado fuertes crisis financieras, depresiones, inflación, burbujas inmobiliarias, despojos y especulación; menciona Harvey que la ciudad ha muerto víctima de su crecimiento urbano sin importarle cuáles sean las posibles consecuencias sociales, medioambientales o políticas (2013, pp. 13-14); por lo que defiende el derecho a la ciudad, el cual es un derecho a cambiar y reinventar la ciudad de acuerdo con nuestros deseos, es un derecho colectivo (p. 20).

El derecho a la ciudad fue uno de los temas más importantes de Henri Lefebvre, pues consideró que la ciudad expresaba y simbolizaba el ser y conciencia de una persona $(2000$, pp. 7-8), al mismo tiempo, observó la crisis de la ciudad y la extensión de lo urbano en el que la ciudad y el país habían sido abolidos (p. 14); sobre la misma cuestión, Gordon apuntó que la sociedad ha establecido reglas tradicionales de conducta y un conjunto de saber artesano o de ciencias prácticas, las cuales han sido aplicadas al ambiente; las tradiciones sociales formadas por la historia de la comunidad son las que determinan la conducta general de los miembros de la sociedad (Gordon Childe, 1996, p. 288).

\section{MARCO TEÓRICO: EDUCACIÓN AMBIENTAL Y SUSTENTABILIDAD}

Otra historia corre paralela. En la Conferencia Intergubernamental de Estocolmo de 1972, sobre Medio Ambiente Humano, se reconoció la existencia de una crisis ambiental a nivel planetario y se creó el Programa de las Naciones Unidas para el Medio Ambiente (PNUMA). En este momento se empezó a difundir la importancia de la educación ambiental como herramienta necesaria para generar conciencia sobre el uso de los recursos naturales (Vélez y Londoño, 2016, p. 176); el mundo está en crisis y la búsqueda de alternativas se ha vuelto una tarea obsesiva entre los sectores más conscientes (Toledo, 2015, p. 36), la educación y la comunicación, entre estos.

En una investigación documental, Sauvé, Brunelle y Berryman, concluyen que uno de los problemas identificados es la tendencia hegemónica de cierto marco de referencia: el de una visión mundial centrada en el crecimiento económico (Sauvé, Brunelle, y Berryman, 2006, p. 87); Cortés y Peña proponen un modelo para entender el desarrollo sustentable, 
como aquel que va del no-desarrollo al desarrollo con crecimiento económico material, y luego, al desarrollo sin crecimiento económico material. Implica el manejo de recursos naturales, humanos, sociales, económicos y tecnológicos, con el fin de alcanzar una mejor calidad de vida para la población (Cortés y Peña, 2015, pp. 50-51).

La educación ambiental está orientada a enseñar cómo los ambientes naturales funcionan y en particular cómo los seres humanos pueden controlar los ecosistemas para vivir de modo sostenible, minimizando la degradación, la contaminación del aire, agua o suelo, y las amenazas a la supervivencia de otras especies de plantas y animales; sus objetivos son: considerar el ambiente de manera integral, asumir un enfoque interdisciplinario, tratar la temática de lo particular a lo general, promover el conocimiento y las habilidades para solucionar los problemas (Frers, 2007). La educación ha tenido tradicionalmente una visión demasiado antropocéntrica, por ello, es necesario un cambio que permita crear otras conciencias para la nueva concepción de interacción ser humano-medio ambiente, el desarrollo de un nuevo sistema de valores (Yebra, Guerrero y Jiménez, 2015, p. 7); en este sentido, la educación ambiental es un proceso que le permite al individuo comprender las relaciones de interdependencia con el entorno en el que se desarrolla y está orientada a la formación de personas críticas y reflexivas con capacidad de comprender la problemática ambiental desde el contexto local, regional y nacional (Morales, 2016, p. 118).

En una investigación documental de Medina y Páramo se encontró que los principales estudios sobre educación ambiental son los relacionados con actitudes, representaciones sociales, constructivismo y aprendizaje significativo, los cuales son centrales en las teorías pedagógicas y psicológicas (Medina y Páramo, 2014, p. 68); por consiguiente, desde el ámbito educativo se llevan a cabo estrategias transversales para incorporar la educación ambiental en el currículum oficial, por ejemplo, el diseño de estrategias didácticas que permitan el conocimiento de las afectaciones ambientales en una localidad (Becerra y Torres, 2014, p. 2); el uso de juegos modificados para entablar una relación directa entre el alumno, su entorno próximo y los problemas ambientales (Sánchez, 2011); la enseñanza interdisciplinaria de la educación ambiental sobre los conocimientos, valores y actitudes ambientales (Torres, Mesina, Salamanca, y Sepúlveda, 2015, p. 1141); en el nivel superior, varias universidades han incorporado diversas materias de manera obligatoria con sellos y características particulares (Ávila, 2014, p. 38).

Sobre el concepto de sustentabilidad, el Manifiesto por la vida menciona que se funda en el reconocimiento de los límites y potenciales de la naturaleza, así como la complejidad ambiental, inspirando una nueva comprensión del mundo para enfrentar los desafíos de la humanidad en el tercer milenio (2002, p. 2). Grupos ecologistas han buscado promover un modo de vida urbano ecológicamente más sensible como una visión alternativa para la 
ciudad (Harvey, 2013, p. 5); el "derecho de los desposeídos a su ciudad, su derecho a cambiar el mundo, a cambiar la vida y a reinventar la ciudad de acuerdo a sus propios deseos" (p.49).Rafael Tonatiuh Ramírez aborda el tema de sustentabilidad y encuentra 22 ejemplos diferenciados de entender y practicar la sustentabilidad, que van desde su base etimológica hasta como responsabilidad y proyecto comunitario (Ramírez Beltrán, Concepciones de la sustentabilidad: Resultados en la operación de Políticas Públicas ambientales y sus implicaciones en la educación ambiental, 2018).

Los temas de educación ambiental y sustentabilidad, poco a poco se han ido insertando en las actividades laborales y cotidianas de la población, por ejemplo: la Organización Mundial del Turismo (OMT) ha reconocido una sensibilización del turista por aspectos ambientales, por lo que cualquier actividad turística tiene que considerar su aspecto ambiental (Ramos y Fernández, 2013, p. 300).

\section{DEL ESPACIO PÚBLICO AL ESPACIO PRIVADO;}

DE LO URBANO A LO DIGITAL

Los ciudadanos requieren de un espacio público ordenado, seguro, limpio, con fuentes de energía renovables, un consumo suficiente a sus necesidades, oportunidades de esparcimiento deportivo y artístico, con escuelas y centros médicos de calidad, solidarios y empáticos con los otros seres humanos y con la naturaleza. Lefebvre (2000), como filósofo utopista, previó una ciudad lúdica, en la cual la vida cotidiana se transformaría, y la gente estaría a cargo de sus vidas, insiste en considerar lo posible imposible, a llevar al extremo las ideas para así aclarar los objetivos y las consecuencias de la elecciones, a que la ciudadanía apunte por una democracia más directa e insiste en pensar la ciudad como una totalidad, como un todo que articula la relación entre elementos. La tarea fundamental es conseguir la pequeñez dentro de una gran organización, a través de la prudencia, que significa saber cuando lo sufiente es suficiente, la prudencia implica una transformación del conocimiento de la verdad en decisiones que corresponden a la realidad (Schumacher, 2001).

Para Lefebvre, la forma de vida es una cualidad de la persona y se vincula con acciones de construcción, pensamiento y discurso, como la moda, la alimentación, el juego (p. 17); la globalización económica está llevando a la privatización de los espacios públicos, el destino de las naciones y de la gente está cada vez más conducido por procesos económicos y políticos que se deciden fuera de sus esferas de autonomía y responsabilidades, el Manifiesto por la vida. Por una ética para la sustentabilidad, expone en el punto 24 lo siguiente: 
El sistema parlamentario de las democracias modernas se encuentra en crisis porque la esfera pública, entendida como el espacio de interrelación dialógica de aspiraciones, voluntades e intereses, ha sido desplazada por la negociación y el cálculo de interés de los partidos que, convertidos en grupos de presión, negocian sus respectivas oportunidades de ocupar el poder (2002, p. 7).

Los efectos negativos de la urbanización han fomentado revoluciones protagonizadas por los más desfavorecidos, por los desempleados que están en contra de la codicia capitalista y la desigualdad; las ciudades se ven cada vez más divididas, fragmentadas y proclives al conflicto con levantamientos y disturbios; por ello, es que surgen los movimientos sociales como un grito de socorro de gente oprimida diciendo ¡Ya basta! (Harvey, 2013); en América Latina se pueden observar problemas con la megaminería a cielo abierto, el agronegocio (cultivos transgénicos, uso de agrotóxicos, producción de biocombustibles), megaemprendimientos energéticos (hidroeléctricas, industria petrolera) y de infraestructura, entre otros (Berger, 2014, p. 194); el caso de los mineros guatemaltecos, donde se generó un alza en los conflictos ambientales entre las comunidades campesinas y empresas transnacionales (Dougherty, 2013, p. 1).

Manuel Castells hace referencia al espacio público como un espacio de deliberación que está ocupado por los intereses de las élites dominantes, por lo que los movimientos sociales han tenido que labrar un nuevo espacio público, no sólo internet y las redes sociodigitales, sino que se haga visible en los lugares donde se desarrolla la vida social; menciona que el espacio de los movimientos sociales se contruye como un espacio híbrido entre las redes sociales de internet y el espacio urbano para rebelarse contra una o varias dimensiones de la dominación social como la explotación económica, la pobreza, la desigualdad, la represión, entre otras, incluida la negligencia hacia el planeta azul (Castells, 2012).

Por otro lado, el poder social surge como una fuerza emancipadora con capacidad de superar la crisis de civilización mediante la acción organizada, consciente y dirigida hacia la regeneración del entramado social; sin embargo, la construcción del poder social comienza en la escala doméstica, en la familia, en la edificación de un hogar autosuficiente, seguro y sano, que comparte con muchos otros hogares una misma micropolítica doméstica (Toledo, 2015, p. 51); el uso de las redes sociodigitales se vuelve un espacio privado para continuar con la comunicación pública (Papacharissi, 2012), el uso de las redes sociodigitales no reemplaza la interacción cara a cara, pero es una oportunidad que han tomado los movimientos sociales para organizarse y comunicarse con la sociedad desde su hogar hasta cualquier parte del mundo, ha servido de medio de información para conocer el estado en que se encuentran las manifestaciones en otros países y que, desafortunadamente, no se observa en las noticias. 
Del mismo modo, el uso de redes sociodigitales es un espacio para que las instituciones, organizaciones civiles y comunidades interactúen con la sociedad, para que los conozcan e identifiquen, informen sobre los nuevos acontecimientos, recuerden fechas, expongan peligros, inviten a eventos masivos, realicen denuncias, entre otras posibilidades que tienen estos medios.

\section{COMUNICACIÓN AMBIENTAL Y REDES SOCIODIGITALES}

El ritmo de las comunicaciones se ha acelerado hasta el punto de volverse instantáneo, no obstante, también aumenta la segregación social (Lefebvre, 2000, p. 19); la inadecuada respuesta de la tecnología a las necesidades sociales ha producido una brecha digital que surge de la dificultad de acceso de gran parte de la población a las nuevas tecnologías, su causa inicial está en la elevada exigencia de educación y especialización que estas llevan asociadas, vinculadas a una sociedad orientada por el conocimiento y la capacidad de innovación (Vergara, 2009, p. 38), a pesar de que el acceso a internet aumenta día con día, esto no garantiza que las personas lo utilicen con fines académicos, profesionales o creativos.

Las teorías de comunicación ponen de manifiesto que los medios tecnológicos son hoy una fuente de difusión difícil de ignorar, tanto como los mensajes que fluyen entre los diferentes actores del proceso comunicativo (Vallejos y Oñate Ñ., 2013, p. 62); por ello, la comunicación como eje de las dinámicas humanas no es ajena a la crisis mundial; por ejemplo, la labor del periodismo ambiental se registra desde la década de los años sesenta, cuando ya los medios informaban sobre los evidentes impactos de la crisis ambiental de la posguerra (Román y Cuesta, 2016, p. 17).

La comunicación ambiental es la transmisión de información sobre el medio ambiente a personas que desconocen esas materias, con la comunicación y la educación ambiental se forma personas con sentido crítico, participativas e involucradas en lo que sucede en su entorno, facilitan la toma de decisiones y el paso a la acción, imprescindible para detener el deterioro del planeta (Verdes Digitales, 2018). La comunicación ambiental ha pasado del olvido en la agenda pública en los medios de común (Carabazá y Lozano, 2007), a tener un papel activo con específicos en programas de radio, televisión, series en streaming y en las redes sociales (Ramírez, Meixueiro y Escobar, 2015).

Por otro lado, la comunicación del riesgo requiere de un proceso iterativo, de retroalimentación, donde los expertos y no expertos compartan discursos sobre la amenaza para reconocer y construir el concepto sobre el cual operarían las acciones para dar cuenta de la 
incertidumbre (Román y Cuesta, 2016,p. 61); ante los desastres naturales, la comunicación de riesgos sería una variable a incluir en el modelo para el estudio del estrés y la resiliencia, ya que un aumento de los eventos de riesgo supone un mayor estrés (Cruz, Juárez, Sandoval, y Bustos, 2017, p. 93); se recomienda el estudio del impacto de la difusión de los medios en la sociedad civil y la construcción de una agenda pública orientada a la prevención de desastres naturales y la reducción de su afectación a la salud comunitaria (García, Carreón, Bustos, Hernández, y Salinas, 2015, p. 78).

Ramírez y Rebeil afirman que la población del planeta, en su generalidad, no tiene comunicación, información confiable, suficiente, disponible y pertinente sobre la crisis ambiental y el papel de la sustentabilidad como alternativa a la misma; además, que la comunicación, como el acto de compartir sentido y significado a través de mensajes, y la educación, con su clara vocación transformadora, tienen todavía una larga agenda pendiente en el caso de lo ambiental (Ramírez y Rebeil, 2012, p. 38); por ejemplo, en una investigación de Fernández, Teso y Piñuel concluyen que el compromiso actual de los medios de comunicación social con la crisis del cambio climático se ha revelado poco eficaz atendiendo a la falta de información y formación precisas que tiene la población en general sobre la verdadera naturaleza del cambio climático (2013, p. 44); igualmente, Rodríguez afirma que la falta de comunicación que existe acerca del problema en todos los niveles es palpable y necesaria para que la población se entere del problema que representa el ruido para la salud y el bienestar y, por otro lado, se pueda crear una conciencia permanente en la población (Rodríguez, 2015, p. 2).

Asimismo, la comunicación ambiental permite adquirir conocimientos básicos y aprender a buscar las informaciones pertinentes para mejorar la comprensión de los fenómenos y de las problemáticas ambientales con el fin de emitir diagnósticos y tomar decisiones acertadas, formando a los individuos para propiciar el cambio de actitudes, valores, prácticas y comportamientos respecto del manejo de los ecosistemas (Aparicio, 2016, p. 228). Del mismo modo, Martínez y Sosa hacen referencia a la comunicación para el desarrollo dentro de una comunidad o espacio determinado, pues es indiscutible cambiar el modelo vigente hegemónico para que no se profundice la crisis ambiental que nos afecta a todos (Martínez y Sosa, 2016, p. 73).

La ética de la sustentabilidad nos confronta con el vínculo de la sociedad con la naturaleza, con la condición humana y el sentido de la vida (Manifiesto por la vida. Por una ética para la sustentabilidad, 2002, p. 7); por ello, la comunicación ambiental debe tener como principio un nuevo pacto social que busque reconstruir las relaciones del ser humano con la naturaleza mediante la solidaridad, el reconocimiento del otro y la diferencia que promuevan el pluralismo (p. 9). 
Los problemas de urbanización en la Ciudad de México comienzan desde la construcción de México Tenochtitlan pero, desde la comunicación, son muchas las opciones que se pueden realizar para tener un modo de vida amigable con el entorno; por ejemplo, el proyecto de ecoalfabetización de Carlos Montoya y Ricardo O. Russo, donde pretenden sembrar una semilla de ética ambiental y social mediante la comprensión y cuidado de los recursos naturales por medio de la comunicación y el manejo integrado de cuencas (2007, p. 84); en Colombia, se propone un ejercicio de deconstrucción discursiva desde la teorías críticas y poscoloniales, con el cual es posible visibilizar y cuestionar las estructuras eurocéntricas y antropocéntricas desde las cuales la naturaleza ha sido cooptada (Pérez, 2016, p. 153).

Para lograr el cambio de actitud y comportamiento es necesario entender la compleja relación ser humano-naturaleza que implica una cadena de valores, creencias y actitudes que son necesarias de analizar y estudiar en contextos específicos, para construir comportamientos adecuados con el ambiente, pero vinculados a la cultura y el territorio, lo que es resultado de un proceso de educación y comunicación ambiental (Román y Cuesta, 2016, p. 33).

Desde 2010 se comenzó el estudio de la influencia y el impacto de las redes sociodigitales en el sector ambiental y son varios los cambios que han ido ocurriendo; la anticipada pérdida de frescura inicial de unas redes clave para el activismo, hasta el punto de jugar un papel importante en las denominadas Trwitter Revolutions, es un ejemplo de la creciente profesionalización y uso corporativo de herramientas que originalmente, en el caso de los blogs, tenían un claro componente de expresión personal (Ruiz, 2016, p. 5).

\section{METODOLOGÍA}

La investigación tiene carácter de exploratoria, siguiendo una metodología mixta, en la parte cuantitativa se evalúa la información que proporcionan las páginas en Facebooky en la parte cualitativa se buscan datos subjetivos, personales y hasta íntimos (creencias, formas de pensar y de reflexionar, emociones, sentimientos, costumbres, hábitos, rituales, hechos cotidianos referidos, etc.) en los comentarios de algunas publicaciones realizadas. Se basa en el análisis de imágenes, representación, discursos y frases; en particular, se recurre a la ciberetnografía, como técnica de investigación, para documentar lo que pasa en los dispositivos ligados con internet, acotando las relaciones a grupos específicos vinculados a una relación, interés o tema.

Domínguez, et al. (2007) señalan que los enfoques cualitativos para indagar en internet son muy recientes y están enfrentando los debates tradicionales del campo y también otro de prácticas éticas e identitarias: 
la etnografía virtual no es un método exclusivo de la antropología. La sociología, la educación, la filosofía, la psicología, la economía o el arte también estudian los fenómenos culturales que guardan relación con estas áreas de interés. Internet es un espacio de interacción que acoge formas de práctica social que pueden derivar en usos diversos y con finalidades igualmente variadas. Son muchas las especialidades que recurren al método etnográfico para aproximarse a sus objetos de estudio. El uso multidisciplinar no solo contribuye a enriquecer la etnografía, sino que puede apoyar en la búsqueda de respuestas a las cuestiones metodológicas planteadas anteriormente. Esta diversidad de enfoques, junto con la recuperación de algunos debates etnográficos clásicos -como las relaciones del investigador con el campo, las cuestiones éticas, el método observacional o la "construcción” del discurso etnográfico (Domínguez, et al., 2007, párr. 4).

En la investigación de la comunicación los estudios etnográficos en internet tienen su origen en los Estudios culturales, particularmente de seguimiento a jóvenes (García, 2012). Desde la comunicación educativa y ambiental este método es usado para:

la transformación de la cultura del texto, la producción de narrativas, la sistematización, análisis y producción de conocimiento en general por parte de los diferentes actores educativos de las universidades. Lévy (1999) denominó a este fenómeno “virtualización del texto”, tratando con ello de contextualizar un objeto —el texto impreso- en una matriz mucho más amplia, que arrancó con la oralidad y en la actualidad salta a la hipertextualidad y la hipermedialidad.

Desde la comunicación educativa y ambiental este método puede ser usado por la explosión de las tecnologías y la evolución del pensamiento y acciones ambientales en este ámbito. El procedimiento utilizado en la investigación fue el siguiente:

1. Se realizó una selección de sitios en Facebook que, explícitamente, se relacionaran con medio ambiente, sustentabilidad y educación y comunicación ambiental.

2. Se registró en una tabla diseñada ad boc la información expuesta en las páginas seleccionadas.

3. Se construyeron categorías de análisis para identificar el tipo de publicaciones en cada perfil, en un lapso de cinco días, del 21 al 25 de octubre de 2019, la información se registró en la misma tabla de concentración de datos diseñada anteriormente.

4. Se realizó el análisis de los resultados para identificar qué tipo de publicaciones predominan en los perfiles. 
Las seis categorías que se utilizaron para ubicar las publicaciones se obtienen de Ramírez, Meixueiro y Escobar (2015):

a) Naturaleza, descripción de algún ecosistema o especie.

b) Ser humano-naturaleza, presencia del ser humano y su contexto; el ser humano en convivencia/desafío/sobrevivencia/subsistencia vinculado con la naturaleza.

c) Relación sociedad-naturaleza, la sociedad en su conjunto y su integración/desintegración, con la naturaleza.

d) Sustentabilidad: alternativas sociales, culturales y tecnológicas a la crisis ambiental; visiones y prácticas distintas; integración de los elementos: la ecología, economía y sociedad.

e) Sobre la crisis ambiental: evidenciar los síntomas de la crisis planetaria ambiental, como: la pérdida de biodiversidad, cambio climático, dominio de la racionalidad económico-industrial, etcétera.

f) Mundo catastrófico o apocalíptico. Prospectivas casi siempre con carga negativa. Aborda las probables consecuencias de la no atención a los llamados síntomas de la crisis ambiental.

\section{RESULTADOS}

Fueron 20 páginas de Facebook identificadas con el medio ambiente, educación ambiental y sustentabilidad; la información general, las aplicaciones que utilizan, su comunidad y las imágenes que se identificaron fue lo expuesto hasta el día 6 de noviembre de 2019. En la tabla 1 se presentan los datos obtenidos.

De acuerdo con el orden de la información de la tabla 1, de izquierda a derecha, se describen a continuación los resultados obtenidos. En la sección de Información se presenta el tipo de organización, el país de origen, las opiniones de los usuarios que se representa con una calificación, la fecha de creación de la página, la dirección, el teléfono, el horario de servicio, el enlace para su página web y otras redes sociodigitales y descripción. El gris claro representa que ese indicador está presente en la página y el gris fuerte su ausencia.

Según el tipo de organización, se trata de páginas gubernamentales, organizaciones sobre el medio ambiente, escuelas públicas y universidades, servicios de ingeniería, organizaciones no gubernamentales, servicio comunitario, organización sin fin de lucro o medios de comunicación; las páginas muestran uno o varios tipos de organización. Hay variantes según como se presenta la institución u organización, según el tipo de descriptores. 


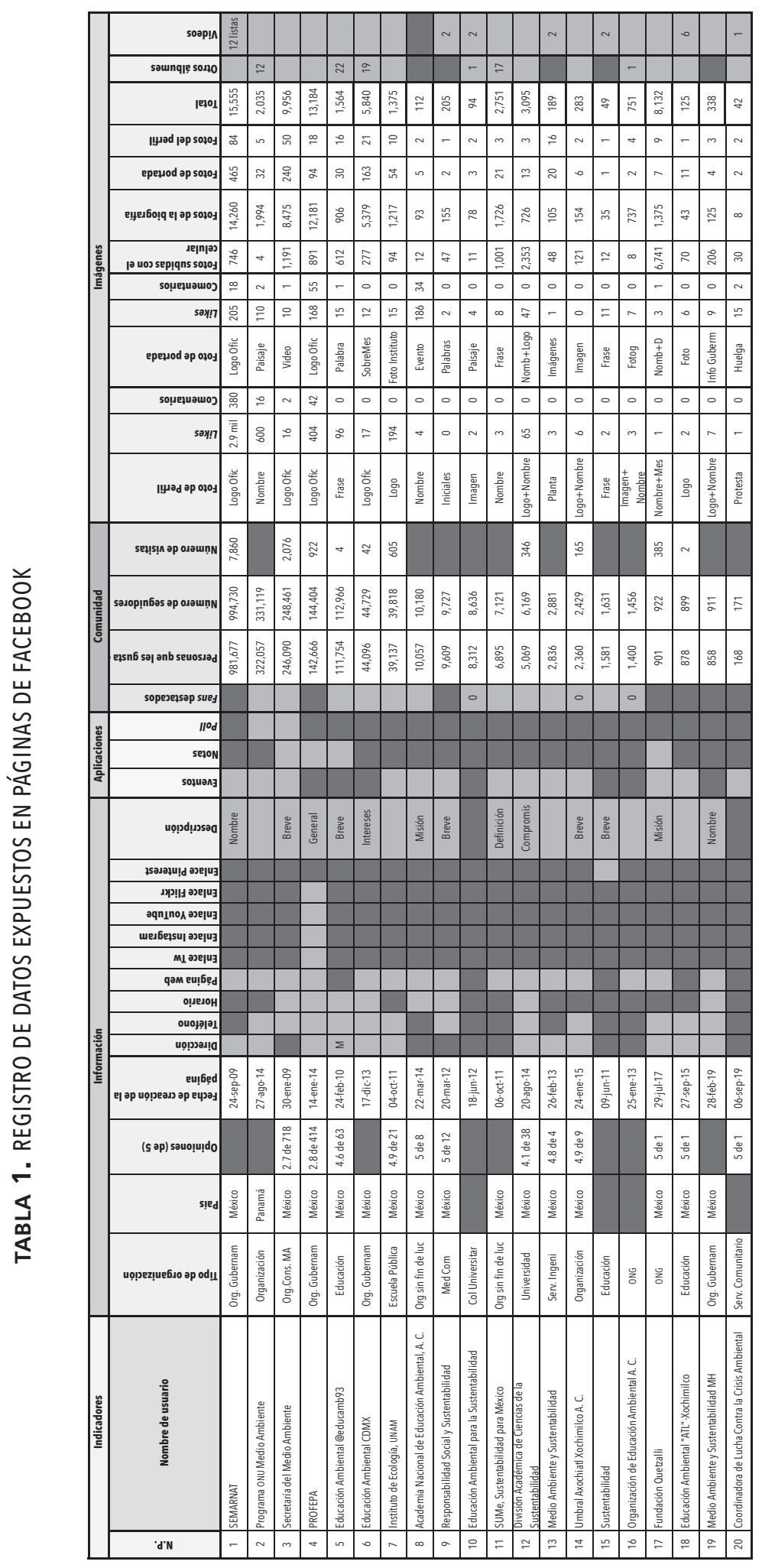

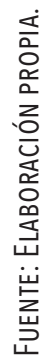


Según el país, 15 son de México, una de Panamá (Programa ONU Medio Ambiente) y cuatro no lo dicen. Sobre las opiniones de los usuarios sobre la página, sólo 12 muestran esta información, la cual va desde 2.7 a 5 de 5 , y gira en torno al número de opiniones que tienen, que también varía, pues en algunas sólo es un usuario el que ha presentado su opinión mientras que en la más alta son 718 usuarios los que opinaron (página de la Secretaría del Medio Ambiente).

Por su fecha de creación, la Gráfica 1 indica que en 2014 fueron cuatro páginas que se crearon: Programa ONU Medio Ambiente (PNUMA), Procuraduría Federal de Protección al Ambiente (PROfEPA), Academia Nacional de Educación Ambiental, A. C. (ANEA) y División Académica de Ciencias de la Sustentabilidad.

GRÁFICA 1. FRECUENCIA POR AÑO DE CREACIÓN DE LAS PÁGINAS DE FACEBOOK

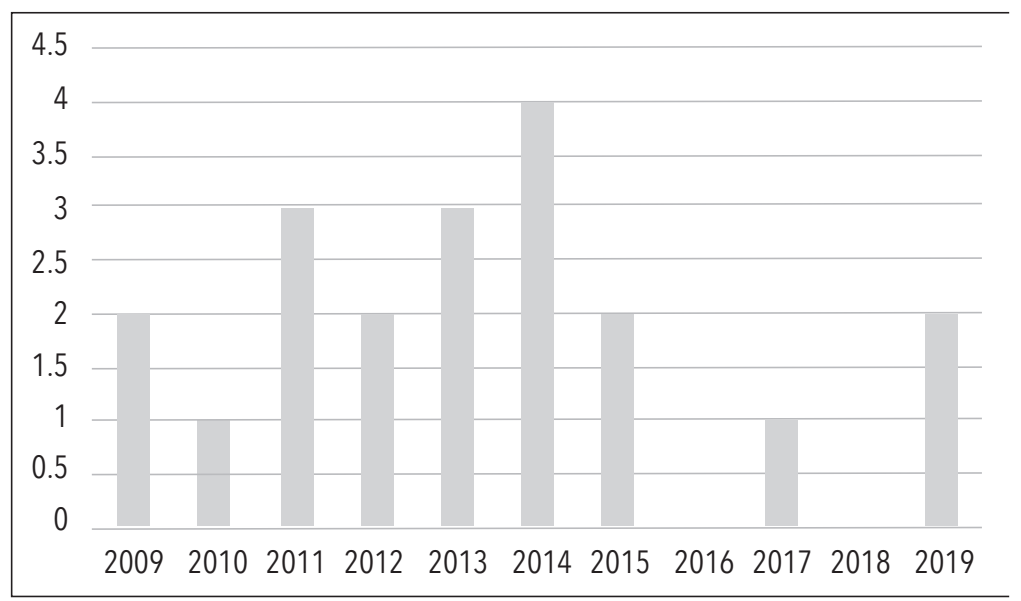

FUENTE: ELABORACIÓN PROPIA.

Sobre información de su institución u organización físicamente como dirección, teléfono y horarios, se encuentra que: 12 páginas sí exponen su dirección, 12 proporcionan su número telefónico, sólo ocho dan su horario de atención; esto pude relacionarse con que algunas páginas son de instituciones de gobierno, escuelas o algún centro de atención.

Sobre los enlaces a su página web y otras redes sociodigitales, se observa que 15 sí tienen página web; y sólo la PROFEPA mantiene sus publicaciones enlazadas a Twitter, Instagram, YouTube y Flickr; mientras que la página de Sustentabilidad tiene enlace con Pinterest; por lo que se puede deducir que páginas como la Secretaría de Medio Ambiente y Recursos Naturales (SEMARNAT), el Programa ONU Medio Ambiente y la Secretaría del Medio Am- 
biente, principales por el número de seguidores que tienen, no han encontrado en Facebook todas sus posibilidades de interacción con los usuarios, esto no significa que no tengan otras redes sociodigitales, sino que no las han enlazado para fortalecer vínculos y comunicación.

Otro elemento importante de la página de Facebook es el de la descripción, pues esta es una oportunidad para decirle a los usuarios sus objetivos, misión, visión, quiénes son, qué hacen y más, es la presentación que se hace de la institución u organización; son 18 páginas de las 20 revisadas que muestran por lo menos el nombre completo de la página, en otros casos, la información es amplia para conocer de qué se trata; Educación Ambiental para la Sustentabilidad y Coordinación de Lucha Contra la Crisis Ambiental no tienen descripción.

Sobre las aplicaciones que manejan como Eventos, Notas y Poll, se encuentra que 13 sí utilizan esta red sociodigital para calendarizar sus eventos y hacer invitaciones; sólo cuatro páginas utilizan las notas para presentar información a los usuarios; y, sólo dos páginas - Programa ONU Medio Ambiente y Secretaría del Medio Ambiente- utilizan Poll para realizar encuestas a los usuarios sobre determinados temas.

En la parte de Comunidad se expone el número de personas que les gusta la página, el número de seguidores, el número de visitas que tienen y el nombre de sus fans destacados, usuarios que siguen más de cerca las publicaciones e interactúan con la página dando un like o escribiendo algún comentario, un premio a esto, es la insignia a la que se hacen acreedores y se puede mostrar a los demás, haciéndolos sentir parte de la comunidad o que su presencia es tomada en cuenta. La tabla 2 muestra los números obtenidos.

TABLA 2. LA COMUNIDAD DE LAS PÁGINAS DE FACEBOOK EXPRESADA EN NÚMEROS

\begin{tabular}{|c|l|c|c|c|c|}
\hline \multirow{2}{*}{ N.P. } & \multicolumn{1}{|c|}{ NOMBRE DE LA PÁGINA } & \multicolumn{3}{|c|}{ COMUNIDAD } \\
\cline { 4 - 6 } & & FANS & $\begin{array}{c}\text { PERSONAS } \\
\text { QUE LES } \\
\text { GUSTA ESTO }\end{array}$ & $\begin{array}{c}\text { NÚM. DE } \\
\text { SEGUIDORES }\end{array}$ & $\begin{array}{c}\text { NÚM. DE } \\
\text { VISITAS }\end{array}$ \\
\hline 1 & SEMAR NAT & & 981,677 & 994,730 & 7,860 \\
\hline 2 & Programa 0 NU Medio Ambiente & & 322,057 & 331,119 & \\
\hline 3 & Secretaría del Medio Ambiente & & 246,090 & 248,461 & 2,076 \\
\hline 4 & PROFEPA & & 142,666 & 144,404 & 922 \\
\hline 5 & Educación Ambiental @educamb93 & & 111,754 & 112,966 & 4 \\
\hline 6 & Educación Ambiental CDMX & & 44,096 & 44,729 & 42 \\
\hline
\end{tabular}




\begin{tabular}{|c|c|c|c|c|c|}
\hline \multirow[b]{2}{*}{ N.P. } & \multirow[b]{2}{*}{ NOMBRE DE LA PÁGINA } & \multicolumn{4}{|c|}{ COMUNIDAD } \\
\hline & & $\begin{array}{c}\text { FANS } \\
\text { DESTACADOS }\end{array}$ & $\begin{array}{c}\text { PERSONAS } \\
\text { QUE LES } \\
\text { GUSTA ESTO }\end{array}$ & $\begin{array}{l}\text { NÚM. DE } \\
\text { SEGUIDORES }\end{array}$ & $\begin{array}{l}\text { NÚM. DE } \\
\text { VISITAS }\end{array}$ \\
\hline 7 & Instituto de Ecología, UNAM & & 39,137 & 39,818 & 605 \\
\hline 8 & $\begin{array}{l}\text { Academia Nacional de Educación Ambiental, } \\
\text { A.C. }\end{array}$ & & 10,057 & 10,180 & \\
\hline 9 & Responsabilidad Social y Sustentabilidad & & 9,609 & 9,727 & \\
\hline 10 & Educación Ambiental para la Sustentabilidad & 0 & 8,312 & 8,636 & \\
\hline 11 & sume, Sustentabilidad para México & & 6,895 & 7,121 & \\
\hline 12 & $\begin{array}{l}\text { División Académica de Ciencias de la } \\
\text { Sustentabilidad }\end{array}$ & & 5,069 & 6,169 & 346 \\
\hline 13 & Medio Ambiente y Sustentabilidad & & 2,836 & 2,881 & \\
\hline 14 & Umbral Axochiatl Xochimilco A. C. & 0 & 2,360 & 2,429 & 165 \\
\hline 15 & Sustentabilidad & & 1,581 & 1,631 & \\
\hline 16 & Organización de Educación Ambiental A.C. & 0 & 1,400 & 1,456 & \\
\hline 17 & Fundación Quetzalli & & 901 & 922 & 385 \\
\hline 18 & Educación Ambiental "Atl"-Xochimilco & & 878 & 899 & 2 \\
\hline 19 & Medio Ambiente y Sustentabilidad MH & & 858 & 911 & \\
\hline 20 & $\begin{array}{l}\text { Coordinadora de Lucha Contra la Crisis } \\
\text { Ambiental }\end{array}$ & & 168 & 171 & \\
\hline \multirow{2}{*}{\multicolumn{2}{|c|}{ NOTA }} & & \multirow{2}{*}{\multicolumn{3}{|c|}{$\begin{array}{l}\text { SÍ SE PRESENTA } \\
\text { NO SE EXPONE }\end{array}$}} \\
\hline & & & & & \\
\hline
\end{tabular}

FUENTE: ELABORACIÓN PROPIA.

Las páginas que muestran más "Me gusta” y seguidores son: SEMARNAT, Programa ONU Medio Ambiente, Secretaría del Medio Ambiente, la PROFEPA y Educación Ambiental, esto puede ser porque son instituciones gubernamentales y en el caso de la ONU es una organización internacional.

Finalmente, se registró el número de imágenes publicadas en cuatro álbumes: fotos de portada, fotos de perfil, fotos subidas con el celular y fotos de la biografía, además, si tenían más álbumes y videos; esto se registra en la tabla 3. 
TABLA 3. IMÁGENES PUBLICADAS EN LA PÁGINA DE FACEBOOK

\begin{tabular}{|c|c|c|c|c|c|c|c|c|}
\hline N.P. & $\begin{array}{l}\text { NOMBRE DE } \\
\text { LA PÁGINA }\end{array}$ & $\begin{array}{l}\text { SUBIDAS CON } \\
\text { EL CELULARR } \\
\end{array}$ & $\begin{array}{c}\text { FOTOS DE LA } \\
\text { BIOGRAFíA } \\
\end{array}$ & $\begin{array}{l}\text { FOTOS DE } \\
\text { PORTADA }\end{array}$ & $\begin{array}{l}\text { FOTOS DEL } \\
\text { PERFIL }\end{array}$ & TOTAL & $\begin{array}{c}\text { OtROS } \\
\text { ÁLBUMES }\end{array}$ & VIDEOS \\
\hline 1 & SEMARNAT & 746 & 14,260 & 465 & 84 & 15,555 & & 12 listas \\
\hline 2 & $\begin{array}{l}\text { Programa ONU } \\
\text { Medio Ambiente }\end{array}$ & 4 & 1,994 & 32 & 5 & 2,035 & 12 & \\
\hline 3 & $\begin{array}{l}\text { Secretaría del } \\
\text { Medio Ambiente }\end{array}$ & 1,191 & 8,475 & 240 & 50 & 9,956 & & \\
\hline 4 & PROFEPA & 891 & 12,181 & 94 & 18 & 13,184 & & \\
\hline 5 & $\begin{array}{l}\text { Educación } \\
\text { Ambiental @ } \\
\text { educamb93 }\end{array}$ & 612 & 906 & 30 & 16 & 1,564 & 22 & \\
\hline 6 & $\begin{array}{l}\text { Educación } \\
\text { Ambiental CDMX }\end{array}$ & 277 & 5,379 & 163 & 21 & 5,840 & 19 & \\
\hline 7 & $\begin{array}{l}\text { Instituto de } \\
\text { Ecología, UNAM }\end{array}$ & 94 & 1,217 & 54 & 10 & 1,375 & & \\
\hline 8 & $\begin{array}{l}\text { Academia } \\
\text { Nacional de } \\
\text { Educación } \\
\text { Ambiental,A.C. }\end{array}$ & 12 & 93 & 5 & 2 & 112 & & \\
\hline 9 & $\begin{array}{l}\text { Responsabilidad } \\
\text { Socialy } \\
\text { Sustentabilidad }\end{array}$ & 47 & 155 & 2 & 1 & 205 & & 2 \\
\hline 10 & $\begin{array}{l}\text { Educación } \\
\text { Ambiental } \\
\text { para la } \\
\text { Sustentabilidad }\end{array}$ & 11 & 78 & 3 & 2 & 94 & 1 & 2 \\
\hline 11 & $\begin{array}{l}\text { SUMe, } \\
\text { Sustentabilidad } \\
\text { para México }\end{array}$ & 1,001 & 1,726 & 21 & 3 & 2,751 & 17 & \\
\hline 12 & $\begin{array}{l}\text { División } \\
\text { Académica de } \\
\text { Ciencias de la } \\
\text { Sustentabilidad }\end{array}$ & 2,353 & 726 & 13 & 3 & 3,095 & & \\
\hline
\end{tabular}




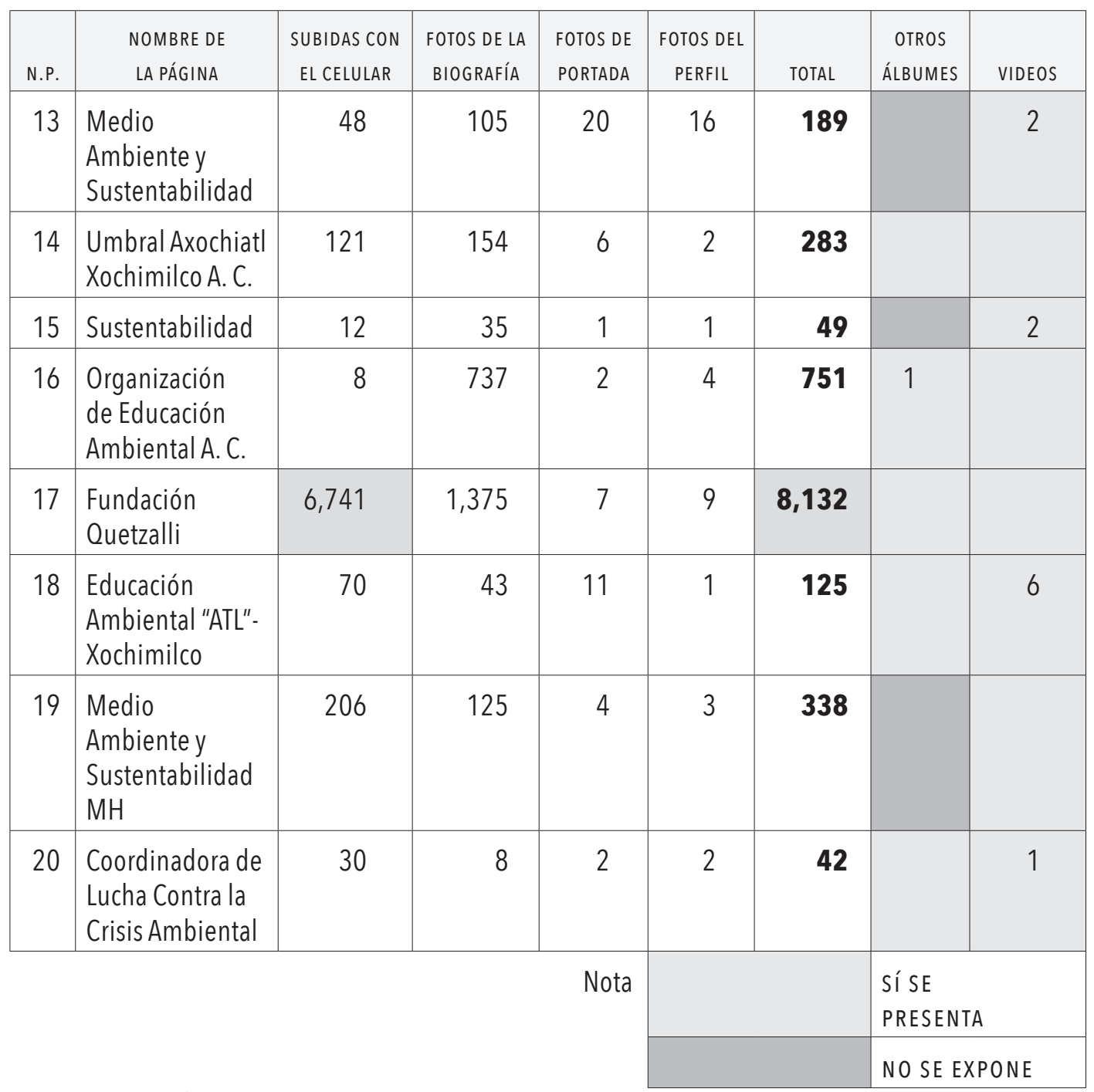

FUENTE: ELABORACIÓN PROPIA.

Son la SEMARnAT, la PROFEPA, la Secretaría del Medio Ambiente, la Fundación Quetzalli y Educación Ambiental CDMX quienes tienen más de 5 mil fotos publicadas, además de tener mayor número de álbumes y videos; en el caso de la SEMARNAT tienen 12 listas de videos en los que constantemente están subiendo videos sobre temáticas específicas. Las imágenes publicadas, ya sean fotografías, información, memes, son de suma importancia pues posibilita tener un acercamiento con los usuarios. 
tabla 4. PUblicaCIONES de ACUERDO CON LAS CATEgORÍAS AMBIENTALES

\begin{tabular}{|c|c|c|c|c|c|c|c|c|c|c|c|c|c|c|c|c|c|}
\hline \multirow[b]{3}{*}{ N.P. } & \multirow[b]{3}{*}{ PÁGINA } & \multicolumn{16}{|c|}{ USOS Y FRECUENCIA } \\
\hline & & \multicolumn{2}{|c|}{ NATURALEZA } & \multicolumn{2}{|c|}{ SER huMANO-NAtURALEzA } & \multicolumn{2}{|c|}{ SOCIEDAD-NATURALEZA } & \multicolumn{2}{|c|}{ SUSTENTABILIDAD } & \multicolumn{2}{|c|}{ CRISIS AMBIENTAL } & \multicolumn{2}{|c|}{$\begin{array}{l}\text { MUNDO DESPUÉS DEL } \\
\text { COLAPSO }\end{array}$} & \multirow[b]{2}{*}{ 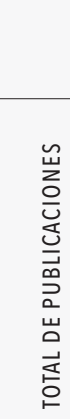 } & \multirow[b]{2}{*}{ 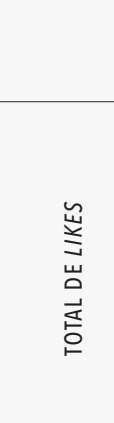 } & \multirow[b]{2}{*}{ 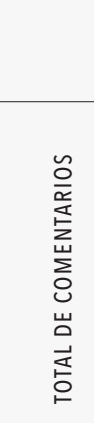 } & \multirow[b]{2}{*}{ 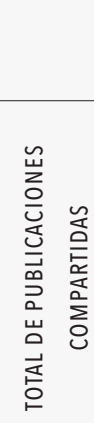 } \\
\hline & & 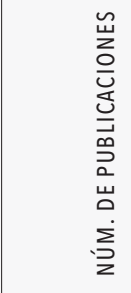 & 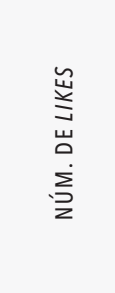 & 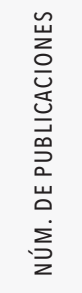 & 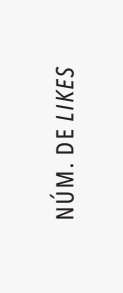 & 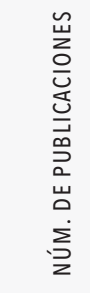 & 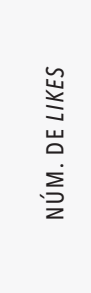 & 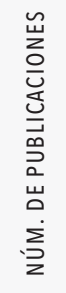 & 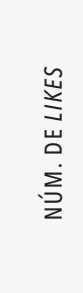 & 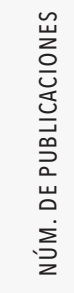 & 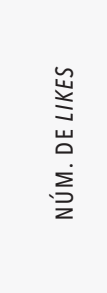 & 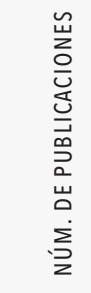 & 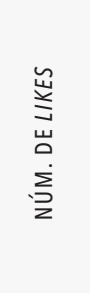 & & & & \\
\hline 1 & SEMARNAT & 16 & 3448 & 1 & 141 & 3 & 105 & 1 & 32 & 5 & 223 & 0 & 0 & 26 & 3949 & 128 & 5 \\
\hline 2 & $\begin{array}{l}\text { Programa ONU } \\
\text { Medio Ambiente }\end{array}$ & 2 & 359 & 0 & 0 & 2 & 817 & 3 & 412 & 5 & 1300 & 0 & 0 & 12 & 2888 & 115 & 1 \\
\hline 3 & $\begin{array}{l}\text { Secretaría del } \\
\text { Medio Ambiente }\end{array}$ & 2 & 248 & 0 & 0 & 8 & 173 & 9 & 230 & 10 & 100 & 0 & 0 & 29 & 751 & 65 & 1 \\
\hline 4 & PROFEPA & 5 & 296 & 0 & 0 & 0 & 0 & 0 & 0 & 2 & 97 & 0 & 0 & 7 & 393 & 25 & 0 \\
\hline 5 & $\begin{array}{l}\text { Educación } \\
\text { Ambiental @ } \\
\text { educamb93 }\end{array}$ & 1 & 7 & 0 & 0 & 0 & 0 & 0 & 0 & 1 & 56 & 0 & 0 & 2 & 63 & 1 & 1 \\
\hline 6 & $\begin{array}{l}\text { Educación } \\
\text { Ambiental CDMX }\end{array}$ & 1 & 19 & 0 & 0 & 0 & 0 & 3 & 84 & 0 & 0 & 0 & 0 & 4 & 103 & 12 & 0 \\
\hline 7 & $\begin{array}{l}\text { Instituto de } \\
\text { Ecología, UNAM }\end{array}$ & 6 & 260 & 0 & 0 & 6 & 44 & 3 & 40 & 2 & 18 & 0 & 0 & 17 & 362 & 17 & 7 \\
\hline 8 & $\begin{array}{l}\text { Academia } \\
\text { Nacional de } \\
\text { Educación } \\
\text { Ambiental, A. C. }\end{array}$ & 0 & 0 & 0 & 0 & 0 & 0 & 0 & 0 & 0 & 0 & 0 & 0 & 0 & 0 & 0 & 0 \\
\hline 9 & $\begin{array}{l}\text { Responsabilidad } \\
\text { Social y } \\
\text { Sustentabilidad }\end{array}$ & 0 & 0 & 0 & 0 & 2 & 5 & 0 & 0 & 1 & 6 & 0 & 0 & 3 & 11 & 1 & 3 \\
\hline
\end{tabular}




\begin{tabular}{|c|c|c|c|c|c|c|c|c|c|c|c|c|c|c|c|c|c|}
\hline \multirow[b]{3}{*}{ N.P. } & \multirow[b]{3}{*}{ PÁGINA } & \multicolumn{16}{|c|}{ USOS Y FRECUENCIA } \\
\hline & & \multicolumn{2}{|c|}{ Naturaleza } & \multicolumn{2}{|c|}{ SER humano-Naturaleza } & \multicolumn{2}{|c|}{ SOCIEDAD-NATURALEZA } & \multicolumn{2}{|c|}{ SUSTENTABILIDAD } & \multicolumn{2}{|c|}{ CRISIS AMBIENTAL } & \multicolumn{2}{|c|}{$\begin{array}{l}\text { MUNDO DESPUÉS DEL } \\
\text { COLAPSO }\end{array}$} & \multirow[b]{2}{*}{ 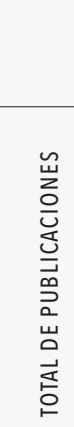 } & \multirow[b]{2}{*}{ 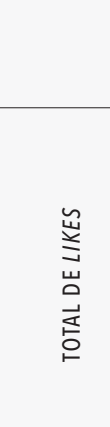 } & \multirow[b]{2}{*}{ 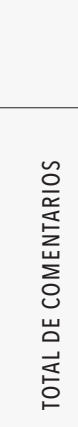 } & \multirow[b]{2}{*}{ 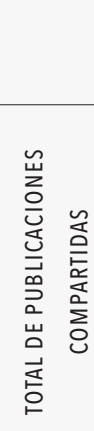 } \\
\hline & & 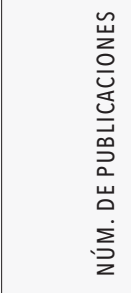 & 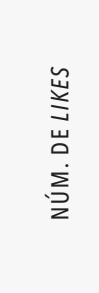 & 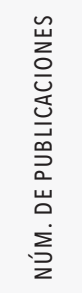 & 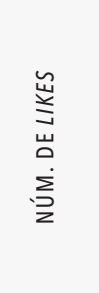 & 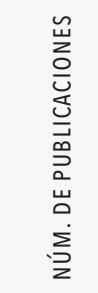 & 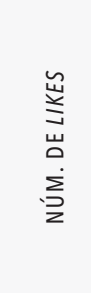 & 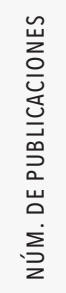 & 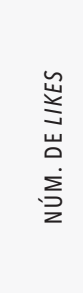 & 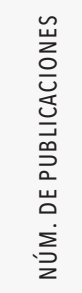 & 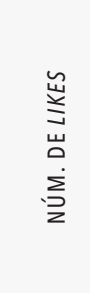 & 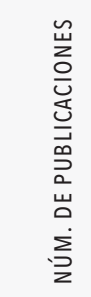 & 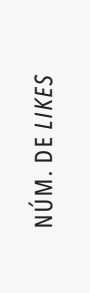 & & & & \\
\hline 10 & $\begin{array}{l}\text { Educación } \\
\text { Ambiental } \\
\text { para la } \\
\text { Sustentabilidad }\end{array}$ & 0 & 0 & 0 & 0 & 0 & 0 & 0 & 0 & 1 & 3 & 0 & 0 & 1 & 3 & 1 & 0 \\
\hline 11 & $\begin{array}{l}\text { SUMe, } \\
\text { Sustentabilidad } \\
\text { para México }\end{array}$ & 0 & 0 & 0 & 0 & 1 & 1 & 9 & 148 & 2 & 26 & 0 & 0 & 12 & 175 & 16 & 0 \\
\hline 12 & $\begin{array}{l}\text { División } \\
\text { Académica de } \\
\text { Ciencias de la } \\
\text { Sustentabilidad }\end{array}$ & 0 & 0 & 0 & 0 & 3 & 8 & 0 & 0 & 0 & 0 & 0 & 0 & 3 & 8 & 1 & 3 \\
\hline 13 & $\begin{array}{l}\text { Medio Ambiente y } \\
\text { Sustentabilidad }\end{array}$ & 5 & 116 & 2 & 31 & 10 & 112 & 2 & 4 & 0 & 0 & 0 & 0 & 19 & 263 & 11 & 19 \\
\hline 14 & $\begin{array}{l}\text { Umbral Axochiatl } \\
\text { Xochimilco A. C. }\end{array}$ & 0 & 0 & 0 & 0 & 1 & 3 & 0 & 0 & 0 & 0 & 0 & 0 & 1 & 3 & 1 & 0 \\
\hline 15 & Sustentabilidad & 0 & 0 & 0 & 0 & 0 & 0 & 0 & 0 & 1 & 24 & 0 & 0 & 1 & 24 & 2 & 1 \\
\hline 16 & $\begin{array}{l}\text { Organización } \\
\text { de Educación } \\
\text { Ambiental A.C. }\end{array}$ & 0 & 0 & 0 & 0 & 0 & 0 & 0 & 0 & 1 & 386 & 0 & 0 & 1 & 386 & 8 & 1 \\
\hline 17 & $\begin{array}{l}\text { Fundación } \\
\text { Quetzalli }\end{array}$ & 2 & 1 & 0 & 0 & 16 & 29 & 3 & 4 & 1 & 1 & 0 & 0 & 22 & 35 & 0 & 5 \\
\hline
\end{tabular}




\begin{tabular}{|c|c|c|c|c|c|c|c|c|c|c|c|c|c|c|c|c|c|}
\hline \multirow[b]{3}{*}{ N.P. } & \multirow[b]{3}{*}{ PÁGINA } & \multicolumn{16}{|c|}{ USOS Y FRECUENCIA } \\
\hline & & \multicolumn{2}{|c|}{ NATURALEZA } & \multicolumn{2}{|c|}{ SER HUMANO-NATURALEZA } & \multicolumn{2}{|c|}{ SOCIEDAD-NATURALEZA } & \multicolumn{2}{|c|}{ SUSTENTABILIDAD } & \multicolumn{2}{|c|}{ CRISIS AMBIENTAL } & \multicolumn{2}{|c|}{$\begin{array}{l}\text { MUNDO DESPUÉS DEL } \\
\text { COLAPSO }\end{array}$} & \multirow[b]{2}{*}{ 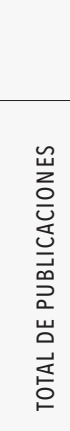 } & \multirow[b]{2}{*}{ 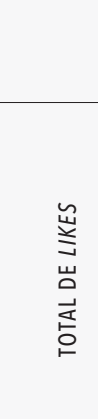 } & \multirow[b]{2}{*}{ 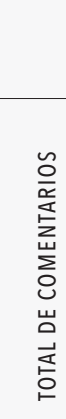 } & \multirow[b]{2}{*}{ 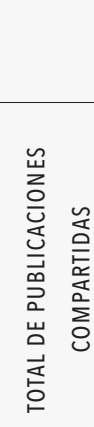 } \\
\hline & & 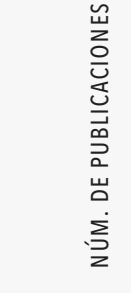 & 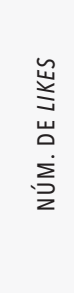 & 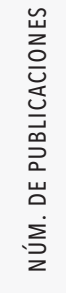 & 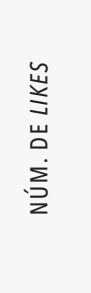 & 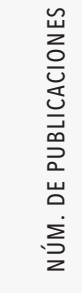 & 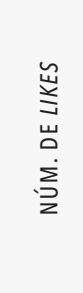 & 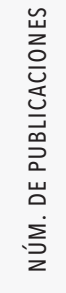 & 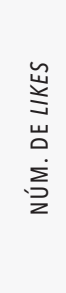 & 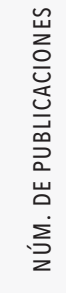 & 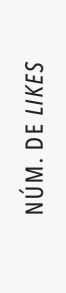 & 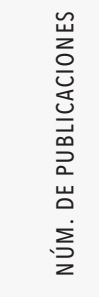 & 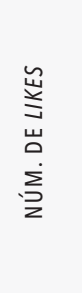 & & & & \\
\hline 18 & $\begin{array}{l}\text { Educación } \\
\text { Ambiental "ATL"- } \\
\text { Xochimilco }\end{array}$ & 1 & 23 & 0 & 0 & 1 & 0 & 0 & 0 & 0 & 0 & 0 & 0 & 2 & 23 & 0 & 1 \\
\hline 19 & $\begin{array}{l}\text { Medio Ambiente } \\
\text { y Sustentabilidad } \\
\text { MH }\end{array}$ & 0 & 0 & 0 & 0 & 11 & 110 & 0 & 0 & 0 & 0 & 0 & 0 & 11 & 110 & 8 & 0 \\
\hline 20 & $\begin{array}{l}\text { Coordinadora de } \\
\text { Lucha Contra la } \\
\text { Crisis Ambiental }\end{array}$ & 0 & 0 & 0 & 0 & 0 & 0 & 0 & 0 & 0 & 0 & 0 & 0 & 0 & 0 & 0 & 0 \\
\hline
\end{tabular}

FUENTE: ELABORACIÓN PROPIA.

Las páginas que presentan mayor número de publicaciones son: Secretaría del Medio Ambiente, SEMARNAT, Fundación Quetzalli, Medio Ambiente y Sustentabilidad y el Instituto de Ecología, UNAM; al contrario, Academia Nacional de Educación Ambiental, A. C. y Coordinadora de Lucha Contra la Crisis Ambiental, no tienen ninguna publicación durante los cinco días de observación.

Las publicaciones de la SEMARNAT, el Programa ONU Medio Ambiente, Secretaría del Medio Ambiente, la PROFEPA y el Instituto de Ecología, UNAM obtuvieron mayor número de reacciones o likes, debido a que estas páginas son más constantes en la publicación de infografías, invitaciones y acciones que realizaron.
Las páginas de la SEMARNAT y Programa ONU Medio Ambiente son quienes tienen mayor número de publicaciones que los usuarios comparten en otras páginas o perfiles, lo que puede expresar que el contenido resulta ser interesante.

Sobre las categorías ambientales, se encontró que la SEMARNAT, la PROFEPA, el Instituto de Ecología, UNAM y Medio Ambiente y Sustentabilidad tienen mayor número de publicaciones sobre la naturaleza, donde se observan infografías sobre especies animales y vegetales, así como fotografías de especies en peligro de extinción.

La Fundación Quetzalli y Medio Ambiente y Sustentabilidad tienen publicaciones sobre la relación Sociedad-Naturaleza, donde se hacen invitaciones a recorrer lugares naturales o se exponen fotografías de encuentros entre las personas y la naturaleza. 
Las publicaciones de SUMe, Sustentabilidad para México tienen que ver con la categoría de Sustentabilidad, pues sus publicaciones son referentes al aprovechamiento de los residuos sólidos, a la vivienda sustentable, a la energía, a ciudades y acciones sustentables.

Por otro lado, la Secretaría del Medio Ambiente tiene mayor número de publicaciones sobre la categoría Crisis ambiental, algunas sobre el programa Hoy No Circula y otras sobre el manejo de los residuos sólidos, fugas de gas, cambio climático y jornadas de limpieza.

Sobre la categoría Ser humano-Naturaleza hay sólo tres publicaciones en total, giran en torno a actividades individuales o logros científicos. Finalmente, de la categoría Mundo después del colapso, no se hizo publicación alguna.

\section{ANÁLISIS Y DISCUSIÓN}

La revisión ciberetnográfica de las páginas seleccionadas permitió identificar como forma de comunicación dominante el uso de infografías, cuadros, fotografías, ilustraciones, videos e invitaciones a eventos; se apuesta por brindar información a los usuarios con diferentes tipos de información, la cual es accesible para diferentes tipos de públicos y didáctica en la presentación de contenidos.

Cabe señalar que es notable el tipo de contenido que algunas páginas publican en mayor cantidad contra la ausencia de actualización de la página en sitios de organizaciones o redes; por ejemplo, la página de la Academia Nacional de Educación Ambiental, A. C. (ANEA), que por su importancia en la sociedad civil en el campo de la educación ambiental debería estar más actualizada, se notó con nulo tránsito informativo en el lapso de la investigación.

Destaca la página de la SEMARNAT, pues siendo una página oficial de una secretaría de Estado, tiene una fuerte actividad en el periodo estudiado, observando así que sus publicaciones más frecuentes son las relacionadas con la categoría Naturaleza, en cambio, son pocas sobre la categoría de Sustentabilidad. En contraste, la organización social sume, Sustentabilidad para México, lo que postea es básicamente sobre la categoría de Sustentabilidad, haciendo referencia a invitaciones a talleres, infografías y eventos de sustentabilidad.

En el tema de la crisis ambiental se identifica como informantes activos una organización internacional y secretarías abocadas a la contención del daño ambiental como la Secretaría del Medio Ambiente, la SEMARnAT y el PNUMA.

Se detectó que, en términos de reacciones, las audiencias activas de la red sociodigital permanecen más activas o prefieren abiertamente el tema de la Naturaleza, pues es donde se observa mayor participación en likes, comentarios y publicaciones compartidas; sin embargo, no todas las páginas tienen publicaciones sobre esta categoría. 
En la categoría catastrofistas o apocalíptica del futuro, a pesar del serio problema del cambio climático, no hay información en ninguna de las páginas revisadas.

\section{CONCLUSIONES}

Los discursos sobre la comunicación y la educación ambiental, así como la sustentabilidad, dada su relevancia en la crisis de civilización, han ido encontrando vías de salida y de divulgación. El internet posibilitó una visibilidad importante que se potenció con las redes sociodigitales. La apuesta de organismos internacionales como el PNUMA, instituciones federales, organizaciones de la sociedad civil y grupos organizados en materia ambiental es tener visibilidad e intercambio en la red sociodigital con más usuarios en el mundo. Sin embargo, es evidente que le da un peso distinto al uso y participación en la red.

Los datos muestran que hay una diferencia en el tipo de información ambiental, la calidad de intercambios, actualización y usuarios. La página de la SEMARNAT domina en seguidores y gustos, así como en visitas, puede ser por la calidad de la información que está presentando o por el peso que está teniendo el secretario de dicha institución dentro del ramo pues cuenta con un reconocimiento de experto a nivel internacional.

Todavía el tema de la sustentabilidad está lejos de ser el dominante en las páginas revisadas. La SEMARnAT, el PNUMA y la Secretaría del Medio Ambiente (CDMX) tímidamente dan cuenta de él, a pesar de que el punto de llegada, desde hace por lo menos tres décadas, sea el desarrollo sustentable como acuerdo internacional.

Por otro lado, la sociedad civil se dedica a otros temas, las organizaciones promueven cursos, talleres y eventos; además de compartir fotografías de las actividades que realizan, algo que se puede rescatar es que sus publicaciones, que en algunos casos son constantes, obtienen poca o nula participación de los usuarios ya que no consiguen ni un like, un comentario o no es compartido; por lo que es necesario aprovechar que ya están dentro del ciberespacio para dar a conocerse a la mayor cantidad de usuarios posible y de esta manera lograr exponer sus objetivos y sus metas, las cuales son dignas de seguir.

De manera general, también se identificó que aun páginas como la SEMARNAT, el Programa ONU Medio Ambiente y la Secretaría del Medio Ambiente con mayor número de seguidores y de publicaciones, no están aprovechando al máximo todas las posibilidades de Facebook, pues no están enlazadas con otras aplicaciones, no todas utilizan las notas, Poll y reconocen a sus fans destacados, lo cual permitiría tener una mejor interacción con el usuario.

Finalmente, hay páginas que no generan contenido, sus publicaciones son compartidas de otras páginas, lo que parecería un copiar y pegar; y, considerando el número de segui- 
dores que tienen las páginas revisadas en esta investigación, todas tienen las posibilidades de crear contenidos informativos sobre los temas del medio ambiente, sustentabilidad y educación ambiental, dando así a sus usuarios información de calidad, oportuna, relevante y significativa que permita mejorar la relación entre el ser humano y los otros y entre el ser humano y el medio ambiente.

\section{REFERENCIAS}

Aparicio Cid, R. (enero-junio de 2016). Comunicación ambiental: aproximaciones conceptuales para un campo emergente. Comunicación y Sociedad (25), 209-235. https://doi.org/10.32870/ cys.v0i25.4427

Ávila Romero, L. (febrero de 2014). Los programas ambientales universitarios en México. Entre el discurso ambiental y los negocios verdes. Sociedad y Ambiente, 1(3), 26-51. Recuperado de http://www.redalyc.org/articulo.oa?id $=455745077002$

Becerra Barón, J., y Torres Merchán, N. (julio-diciembre de 2014). El diseño de material didáctico como aporte al abordaje de los problemas ambientales en entornos educativos y comunitarios. Educación, 38(2), 1-18. Recuperado de http://www.redalyc.org/articulo.oa?id=44031370001 https://doi.org/10.15517/revedu.v38i2.15258

Berger, M. (septiembre-diciembre de 2014). Redes de luchas ambientales en América Latina. Problemas, aprendizajes y conceptos. Argumentos (76), 193-215.

Bonilla, M. (21 de enero de 2019). Las 26 personas más ricas del mundo poseen la misma riqueza que media bumanidad. Recuperado de https://www.vaticannews.va/es/mundo/news/2019-01/informe-oxfam-ong-pobreza-ricos-milmillonarios-26-desigualdad.html

Carabazá, J. y Lozano, J. (2009). Comunicación y Medio Ambiente. Reflexiones, análisis y propuesta. Centro de Investigación en Comunicación e Información. Instituto Tecnológico de Estudios Superiores de Monterrey, pp. 2-18. https://doi.org/10.24265/cian.2013.n3.02

Castells, M. (2012). Redes de indignación y esperanza. España: Alianza Editorial.

Cortés Mura, H., y Peña Reyes, J. (enero-junio de 2015). De la sostenibilidad a la sustentabilidad. Modelo de desarrollo sustentable para su implementación en políticas y proyectos. Revista Escuela de Administración de Negocios(78),40-54. Recuperado de http://www.redalyc.org/articulo. oa?id=20640430004 https://doi.org/10.21158/01208160.n78.2015.1189

Cruz García, L., Juárez Nájera, M., Sandoval Vázquez, F., y Bustos Aguayo, J. (julio de 2017). Una aproximación psicológica a la complejidad ambiental: Especificación de un modelo de estrés y resiliencia comunitaria. Comunitania, 75-95. https://doi.org/10.5944/comunitania.14.5

Domínguez, D., Beaulieu, A., Estalella, A., Gómez, E., Schnettler , B., y Read, R. (septiembre de 2007). Etnografía virtual. Forum Qualitative Sozialforscbung, 8(3). Recuperado de http:// nbn-resolving.de/urn:nbn:de:0114-fqs0703E19 
Dougherty, M. (septiembre de 2013). Complejizando los conflictos ambientales en el altiplano guatemalteco. Letras Verdes. Revista Latinoamericana de Estudios Socioambientales(14), 160-183. https://doi.org/10.17141/letrasverdes.14.2013.1019

Fernández Reyes, R., Teso Alonso, G., y Piñuel Raigada, J. (2013). Propuestas de Soluciones en La Comunicación del Cambio Climático. Razón y Palabra, 22-47. https://doi.org/10.4185/ rlcs-2017-1213

Frers, C. (17 de noviembre de 2007). Ecoportal. Recuperado de https://www.ecoportal.net/temas-especiales/educacion-ambiental/el_desarrollo_de_una_educacion_ambiental/

García Canclini, N., Cruces, F., y Urteaga, M. (2012). Fóvenes, culturas urbanas y redes digitales. España: Ariel.

García Lirios, C., Carreón Guillén, J., Bustos Aguayo, J., Hernández Valdés, J., y Salinas Torres, R. (abril de 2015). Especificación de un modelo de comunicación de riesgos ambientales ante el cambio climático. Entreciencias: diálogos en la Sociedad del Conocimiento, 3(6), 71-89. Recuperado de http://www.redalyc.org/articulo.oa?id=457644944006 https://doi.org/10.21933/j. edsc.2015.06.083

Gordon Childe, V. (1996). Los orígenes de la civilización. México: Fondo de Cultura Económica.

Harvey, D. (2013). Ciudades rebeldes. Del derecbo de la ciudad a la revolución urbana. Madrid:Ediciones Akal. https://doi.org/10.35428/cds.v0i1.11

Horkheimer, M., y Adorno, T. (1998). Dialéctica de la Ilustración. Fragmentos filosóficos. Valladolid: Trotta.

Lefebvre, H. (2000). Writings on Cities. Massachusetts: Blackwell Publishers Inc.

Leff, E. (enero-marzo de 2011). Sustentabilidad y racionalidad ambiental. Revista Mexicana de Sociología, 73(1), 5-46.

Lipovetsky, G. (2007). La felicidad paradójica. Ensayo sobre la sociedad del hiperconsumo. Barcelona: Anagrama.

Manifiesto por la vida. Por una ética para la sustentabilidad. (2002). Ambiente y Sociedad, 1-14. https://doi.org/10.1590/s1414-753x2002000100012

Martínez Beleño, C., y Sosa Gómez, M. (2016). Aportaciones y diferencias entre comunicación en salud, comunicación para el desarrollo y para el cambio social. Revista de Comunicación y Salud, 6, 69-80. Recuperado de https://www.researchgate.net/publication/311800619 https://doi. org/10.15665/esc.v11i2.117

Martínez Castillo, R. (2012). Ensayo crítico sobre educación ambiental. Diálogos Educativos, 70 104.

Medina Arboleda, I., y Páramo, P. (enero-junio de 2014). La investigación en educación ambiental en América Latina: un análisis bibliométrico. Revista Colombiana de Educación(66), 55 72. Recuperado de http://www.redalyc.org/articulo.oa?id=413635257003 https://doi.or$\mathrm{g} / 10.17227 / 01203916.66$ rce 55.72

Montoya, C.,y Russo, R. (agosto-diciembre de 2007).Eco-alfabetización: una herramienta de Educación Ambiental. Revista omunicación, 16, 83-85. Recuperado de https://www.researchgate. net/publication/236650836 
Morin, E., y Kern, A. (2006). Tierra Patria. Buenos Aires: Nueva Visión.

Papacharissi, Z. (2012). A Private Sphere. Democracy in a Digital Age. USA: Polity Press.

Pérez Marín, M. (abril-julio de 2016). El discurso ambiental en Colombia: una mirada desde el Análisis Crítico del Discurso. Chasqui. Revista Latinoamericana de Comunicación(131), 139158. Recuperado de https://revistachasqui.org/index.php/chasqui/article/view/2634 https:// doi.org/10.16921/chasqui.v0i124.21

Pita Morales, L. (enero-diciembre de 2016). Línea de tiempo: Educación ambiental en Colombia. Revista Praxis, 12, 118-125. https://doi.org/10.21676/23897856.1853

Ramírez Beltrán, R. (2018). Concepciones de la sustentabilidad: Resultados en la operación de Políticas Públicas ambientales y sus implicaciones en la educación ambiental. En O. Vázquez Guzmán, y M. Carrillo Huerta, Desarrollo sostenible: Educación ambiental, experiencias prácticas y evaluación de las políticas públicas (pp. 29-41). Puebla: Montiel y Soriano. https://doi.or$\mathrm{g} / 10.2307 / \mathrm{j} . c t v n 96 f 8 c .5$

Ramírez Beltrán, R., y Rebeil Corella, M. (2012). Comunicación ambiental estratégica. Bases teóricas para la incorporación a las organizaciones y a las políticas públicas. En J. Ramos Rodríguez, y E. Molina Carmona, Comunicación ambiental en México (pp. 37-50). Puebla: Montiel y Soriano. https://doi.org/10.4185/cac94

Ramírez, R., Meixueiro, A., y Escobar, O. (2015). Cine y Educación Ambiental. México: La Zonámbula/Universidad Pedagógica Nacional 095.

Ramos Guzmán, A., y Fernández , G. (2013). La educación ambiental: un instrumento para el turismo sustentable. Revista Hospitalidade, X(2), 296-312.

Rodríguez Manzo, F. (septiembre-noviembre de 2015). Ruido ambiental, comunicación y normatividad en la Ciudad de México. Razón y Palabra(91), 1-23. Recuperado de http://www.redalyc. org/articulo.oa?id=199541387021

Rojas, Julio, y Salazar J. (2012). Cibercultura: una forma contemporánea de comunicación multimedia. Análisis. Revista Colombiana de Humanidades, núm. 81, julio-diciembre, 2012, pp. 167-190. Universidad Santo Tomás Bogotá, Colombia.

Román Núñez, Y., y Cuesta Moreno, O. (2016). Comunicación y conservación ambiental: avances y retos en Hispanoamérica. Revista Latina de Comunicación Social(71), 15-39. https://doi. org/10.4185/rlcs-2016-1082

Ruiz Robles, R. (2016). Documento final del grupo de trabajo Comunicación Ambiental 2.0. Congreso Nacional del Medio Ambiente, (p. 59). Madrid.

Sánchez Paredes, A. (octubre de 2011). La Educación Ambiental con enfoque transversal y lúdico para cuarto grado de la escuela primaria: un Proyecto de Intervención. Claroscuros en la Educación. Revista electrónica de Educación. Recuperado de http://palido.deluz.mx/articulos/437 https://doi.org/10.12795/ie.2018.i89.05

Sauvé, L., Brunelle, R., y Berryman, T. (enero-agosto de 2006). Educar para el debate. Políticas nacionales y educación ambiental.Trayectorias, VIII(20-21), 74-88. Recuperado de http://www. redalyc.org/articulo.oa?id $=60715248008$

Schumacher, E. (2001). Lo pequeño es hermoso. Madrid: Tursen/Hermann Blume. 
Soto Cortés, J. (enero-junio de 2015). El crecimiento urbano de las ciudades: enfoques desarrollista, autoritario, neoliberal y sustentable. Paradigma económico, 7(1), 127-149. Recuperado de https://paradigmaeconomico.uaemex.mx/article/view/4840

Toledo, V. (2015). ¿De qué hablamos cuando hablamos de sustentabilidad? Una propuesta ecológico político. Interdisciplina, 3(7), 35-55. https://doi.org/10.22201/ceiich. 24485705e.2015.7.52383

Torres Rivera, L., Mesina Calderon, N., Salamanca Salazar, B., y Sepúlveda Sepúlveda, C. (2015). Efectos de la enseñanza interdisciplinaria en la educación ambiental sobre los conocimientos, valores y actitudes ambientales de estudiantes de segundo ciclo básico (Los Ángeles, Región del Biobío, Chile). Revista Complutense de Educación, 27(3), 1139-1155. https://doi.org/10.5209/ rev_RCED.2016.v27.n3.47551

Vallejos Romero, A., y Onate, M. (2013). Comunicación de riesgos ecológicos: el caso de la contaminación atmosférica en dos ciudades intermedias del sur de Chile. Revista internacional de contaminación ambiental, 29(1), 59-75.

Vélez Rojas, Ó., y Londoño Pineda, A. (2016). De la educación ambiental hacia la configuración de redes de sostenibilidad en Colombia. PERFILES EDUCATIVOS, XXXVIII(151), 175-187. Recuperado de http://www.redalyc.org/articulo.oa?id=13243471011 https://doi.org/10.22201/ iisue.24486167e.2016.151.54923

Verdes Digitales. (19 de septiembre de 2018). Comunicación ambiental para transformar la sociedad. Recuperado de https://verdesdigitales.com/2018/09/19/comunicacion-ambiental-transformar-sociedad/ https://doi.org/10.18566/comunica.n38.a01

Vergara, A. (2009). Territorios inteligentes. Ambienta, 34-58.

Yebra Rodríguez, A., Guerrero, F., y Jiménez Tello, M. (1 de julio de 2015).Las bases de la educación ambiental. Iniciación a la Investigación. Revista electrónica de la Universidad de faén, 1-12. Recuperado de https://www.researchgate.net/publication/281407528 https://doi.org/10.18172/ redur.4007 